\title{
Synthesis of the Selectively Protected Garamine Derivatives as Aminoglycoside Intermediates
}

\author{
Man Sik Moon, ${ }^{\dagger}$ Sook Jin Jun, ${ }^{\dagger}$ So Ha Lee, Chan Seong Cheong, Kwan Soo Kim, ${ }^{\dagger}$ and Byung Suk Lee ${ }^{\ddagger}$ \\ Medicinal Chemistrv Research Center, Life Science Division. Korea Institute of Science and Technologv. \\ P.O. Box 131. Cheongrvang. Seoul 130-650. Korea \\ ${ }^{\dagger}$ Deparment of Chemistr, Yonsei Cniversity, Shinchon 134, Seoul 120-7+9, Korea \\ KKumgdong Pharmaceutical Co., Ltd. 535-3, Daevangri. Kangammvu, Hwasungsi. Gveonggido 445-931, Korea \\ Recened Wowember 6, 2002
}

Key Words : Aminoglỵcoside. Garamine. Antibiotics. Sisomicin

The aminoglycoside antibiotics ${ }^{1}$ are a large and diverse class of carbohydrate-based substances which have been used in the clinical application for ailments such as tuberculosis and septicemia. Also, many aminoglycosides exhibit inhibitory activity against HIV virus. ${ }^{2}$ Various aninoglycoside antibiotics such as kanamycin ${ }^{3}$ in 1957. gentanicin in 1964, sisomicin in 1970. netilnicin ${ }^{6}$ in 1975. isepamicin ${ }^{7}$ in 1978 and arbekacin ${ }^{8}$ in 1987 have been intensively investigated and marketed since development of streptomycin by Waksman in 1944.

Although resistance ${ }^{10}$ and the risk of serious side-effects ${ }^{11}$ in ototoxicity and nephrotoxicity have lessened their use in recent years, these drawback have been met with improved dosing regimens and have stimulated the development of semi-synthetic derivatives such as isepamicin and arbekacin. Isepamicin is a novel broad-spectrum aminoglycoside which possesses high level of stability to aminoglycoside inactivating enzymes and low level ${ }^{12}$ of toxicity to the kidney and inner ear.

The ready availability of suitably protected garamine derivatives $4^{13}$ made it possible to contemplate the synthesis not only of isepamicin. but also other aminoglycoside derivatives. With these objectives in mind, the synthesis and selective protection of garamine was undertaken for synthesis of isepamicin.

Our synthesis was started with sisomicin 1 which was selectively protected by $N$-(benzy losycarbonyloxy)succinimide (N-BCSI) using template effect ${ }^{1+}$ between zinc acetate and the pairs of the neighboring amino group and the hydroxy group of sisomicin. Reaction of L-isoserine derivative 9 with dicyclohexylcarbodiimide (DCC) in the presence of hydroxybenzotriazole (HOBT) and methanol afforded the coupling product $3 \mathrm{in} 80 \%$ yield. The 3"-amine group of the compound 3 was subsequently protected by $N$-(benzyloxycarbonyloxy)succinimide and hydrolyzed in sulfuric acid to afford the garamine derivative + in high yield (Scheme 1). LIsoserine derivative 9 was synthesized as shown in Scheme 2. L-Isoserine $\mathbf{5}$ was reacted with benzyloxycarbonyl chloride in the prescence of $\mathrm{K}_{2} \mathrm{CO}_{3}$ and water to give $N$-protected isoserine 6 in $75 \%$ yield.

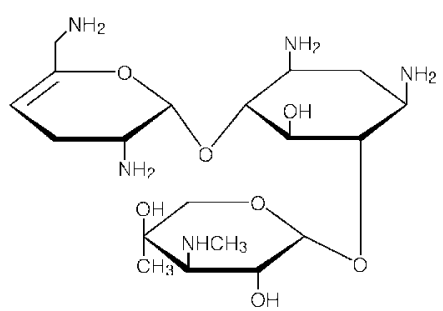

(1)

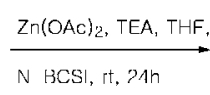

$N$ BCSI, rt, 2Ah

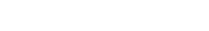

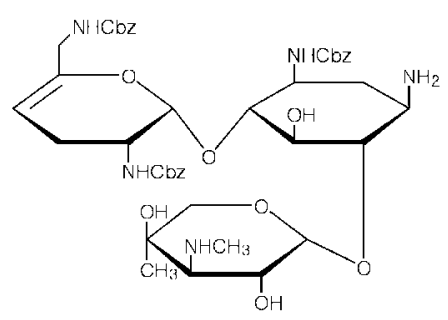

(2), $65 \%$ yield

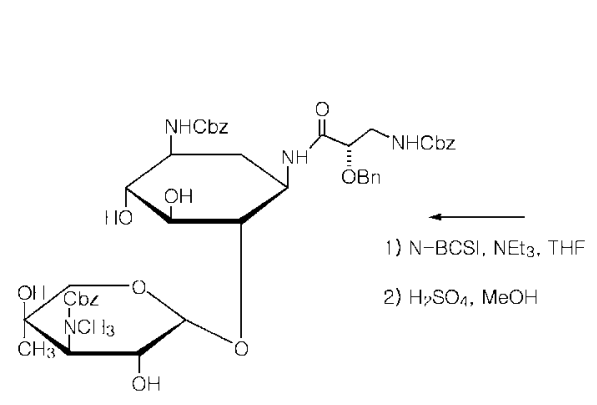

(4), $75 \%$ yield

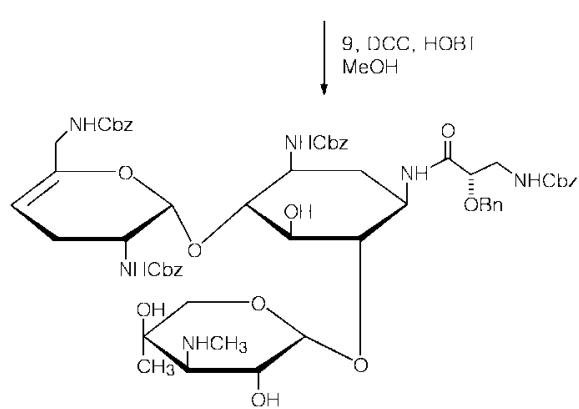

(3), $80 \%$ yield

Scheme 1. Synthesis of garamine derivative 4 


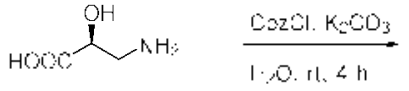

(5)
(6). $75 \%$ yeld

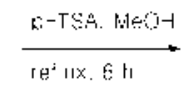

$\mathrm{KOH}, \mathrm{MlOCH}$<smiles>C#CC(=O)NCC(O)C(=O)OCc1ccccc1</smiles>

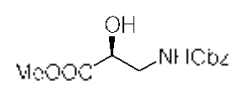

(7). $95 \%$ yield $\mathrm{Ag} O \cdot \mathrm{enE}_{1}$
$\mathrm{TI} \cdot \mathrm{F} \cdot \mathrm{H} \cdot \mathrm{Gr}$

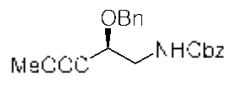

(8). $75 \%$ y eld

Scheme 2. Synthesis of isoserine derivative 9.

The compound 8 was synthesized in the reaction of the acid 6 with $p$-toluenesulfonic acid in methanol, followed by the reaction of 7 with silver (I) oxide and benzyl bromide in THF. The isoserine derivative 9 was synthesized funally by hydroly sis in $90 \%$ yield (Scheme 2).

In conclusion. we have successfully prepared the new garamine derivatives 4 in total yield of $39 \%$ in 4 steps as an intermediate for the synthesis of isepanicin. Also, the new analogue is capable to be used for development of new aminoglycoside antibiotics. Currently. synthesis of isepamicin is on study. using glycosidation reaction of the garamine derivative 4 (glycosyl acceptor) with glycosyl donor.

Acknow ledgment. This work was supported by a grant of Kyungdong Pharmaceutical Co., Ltd.

\section{References}

1. (a) Unezawa, H: Hooper. I. R. Ammoghcoside Amibiotics: Springer-Verlag: Berlin. Heidelberg. New York. 1982. (b) Umezawa. S.: Kondo. S.: Ito. Y. Aminogtvooside Antibiotics: Rehm. H.-J.. Reed. G.. Eds.: Biotechnology Vol. 4. Weinheim: VCH Verlagsgesellschaft: 1986: pp 309-357.

2. Park. W. K.: Auer M.: Jaksche. H: Wong C.-H. $J$. Am. Chem. Soc. 1996, 118. 10150-10155.
3. Takeuchi. T.: Hikiji. T.: Nitta. T.: Yamazaki. S.: Abe S.: Takayama. $\mathrm{H}$ : Umezawa, H. J. Antibio (Tohyo). 1957, .110. 107-114.

4. Weinstein. M. J.: Leudemann, G. M.: Oden, E. M.; Wagman. H Antimicrob. Agents Chemother. 1967. 94, 789-790.

5. Weinstein. M. J.: Marquez. J. A.: Testa. R. T.: Wagmant. G. H.: Oder1. E. M.: Waitz. T. A. J.Ambiot (Tokyo). 1970. 23.551-554.

6. Wright. T. T. Chent Conmum. 1976. 206-208.

7. Nagabhushan. T. L.: Cooper, A. B.; Tsai, H.; Daniels, P. J. L.: Miller. G. H. J. Antibiot 1978.31,681-687.

8. Watanabe. T.: Goi, H.: Hara. T.; Sugano. T: Tanaka. Y.: Kazuno. Y: Matsuhashi. Y: Yamamoto. H.: Yokota. T. Jpn. J. Antibiot. 1987. 40. 349-356 (Tapanese).

9. Schatz. A.: Bugie. E.: Waksman. S. A. Proc. Soc. Exp. Biol. Med. 1944. $55,66-69$.

10. Heinemann. J. A.: Ankenbauer. R. G.: Amábile-Cuevas, C. F. DDT 2000, 5. 195-204.

11. (a) Stnith. C. R.: Lipsky. J. T.: Lietnant. P. S. Antmicrob. Agents Chentother. 1979. 15.780-782. (b) Ohtani. I.: Ohtsuki. K.: Omata. T.: Ouchi. J.: Saito. T. Chentotherapy (Tohyo) 1977. 25. 23482360.

12. Jones. R. N. J. Chemotherapy 1995, 7(Suppl. 2), 7-16.

13. Kugelman, M.: Mallams. A. K: Vernay. H. F: Crowe. D. F.: Tanabe. M. d. Chem. Soc. Parkin Trans. I 1976. 1088-1097.

14. (a) Lee. S. H.: Cheong. C. S. Tetrahedron 2001. 57. 4801-4815 (b) Nagabhushan1. T. L.: Cooper. A. B.: Turner. W. N.: Tsai. H.: MeCombie. S.: Mallams. A. K.: Rane. D.; Wright. J. J.: Reichert. P.: Bosler. D. L.; Weinstein, J. J. Am. Chem Soc. 1978. 100, 52535254. 